\title{
Adsorptive Removal Methylene-Blue Using Zn/Al LDH Modified Rice Husk Biochar
}

\author{
Aldes Lesbani, ${ }^{1,2}$, Patimah Mega Syah Bahar Nur Siregar ${ }^{2}$, Neza Rahayu Palapa ${ }^{1}$, \\ Tarmizi Taher ${ }^{2}$, Fahma Riyanti ${ }^{3}$ \\ ${ }^{1}$ Graduate School of Mathematics and Natural Sciences, Faculty of Mathematics and Natural Sciences, \\ Universitas Sriwijaya, Jl. Palembang Prabumulih Km.32 Ogan Ilir 30662, Indonesia \\ ${ }^{2}$ Research Center of Inorganic Materials and Coordination Complexes, Faculty of Mathematics and Natural Sciences, \\ Universitas Sriwijaya, Jl. Palembang Prabumulih Km. 32 Ogan Ilir 30662, Indonesia \\ ${ }^{3}$ Department of Chemistry, Faculty of Mathematics and Natural Sciences, Universitas Sriwijaya, \\ Jl. Palembang Prabumulih Km. 32 Ogan Ilir 30662, Indonesia
}

Received:22 June 2020

Accepted: 28 November 2020

\begin{abstract}
Composite based Zn/Al layered double hydroxide and biochar was successfully synthesized by liquid deposition treatment following characterization using x-ray, infrared, nitrogen adsorption desorption, thermal, and morphology analyses. Composite was used as removal agents of methylene blue in aqueous solution. Factors that influencing adsorption such as $\mathrm{pH}$ medium, adsorption time, initial concentration, and temperature adsorption were studied systematically. The performance of adsorbent was evaluated by adsorption regeneration process. The results showed that composite has diffraction peak at $10.10^{\circ}$ and $21.30^{\circ}$ due to diffraction of $\mathrm{Zn} / \mathrm{Al}$ and biochar. Composite has higher surface area properties $\left(58.461 \mathrm{~m}^{2} / \mathrm{g}\right)$ than $\mathrm{Zn} / \mathrm{Al}$ layered double hydroxide $\left(9.621 \mathrm{~m}^{2} / \mathrm{g}\right)$ and biochar $\left(50.936 \mathrm{~m}^{2} / \mathrm{g}\right)$. Thermal analysis showed that composite has two endothermic peaks at $90^{\circ}$ and $120^{\circ} \mathrm{C}$ also one exothermic peak at $500^{\circ} \mathrm{C}$. Methylene blue removal on composite was achieve at $\mathrm{pH} 5$ and follow PS-O kinetic model with $k_{2}$ lower than starting materials. The adsorption energy of composite in the range of $17.309 \mathrm{~kJ} / \mathrm{mol}$ and categorized as physical adsorption. Composite has high reusability of adsorbent until three cycles process without loss significant adsorption ability, which has different with biochar and $\mathrm{Zn} / \mathrm{Al}$ layered double hydroxide.
\end{abstract}

Keywords: composite, $\mathrm{Zn} / \mathrm{Al}$, biochar, adsorption, methylene blue

\section{Introduction}

The presence of hazardous synthetic dyes in waste water released from industrial process such as cosmetic,

*e-mail: aldeslesbani@pps.unsri.ac.id

textile, leather, painting, food, and drug industries is serious problem due to not only human health but also aquatic ecosystem [1]. Synthetic dyes are very toxic and carcinogenic due to difficult to degrade and stable under light and oxidation process, thus removal of dyes from wastewater is crucial [2]. Treatment to remove or to reduce concentration of dyes from wastewater has been 
attempted by many researchers using various methods such as filtration, biological treatment, membrane separation, and also adsorption [3, 4]. Adsorption is a suitable method among these ways because this method is simple, fast, and also efficient to remove dyes from aqueous solution [5]. The effectivity of adsorption is very depending on properties of adsorbent. Numerous adsorbents have been tested to remove dyes from aqueous solution such as bentonite, clay, zeolite, biochar, chitosan, and also layered double hydroxide [6-8].

Layered double hydroxide (LDH) is layered material with consist structure from divalent and trivalent metal ions from layer with anion between interlayer space. The anion on interlayer space can be exchangeable depending on synthetic condition and aim of application. The common anion on interlayer LDH is sulfate, carbonate, hydroxide, nitrate, chloride, and also big size anion such as polyoxometalate. The general formula of $\mathrm{LDH}$ can be written as $\left[\mathrm{M}^{2+}{ }_{1-\mathrm{x}} \mathrm{M}^{3+}{ }_{\mathrm{x}}(\mathrm{OH})_{2}\right]+\mathrm{xA}_{\mathrm{x}}{ }^{-\mathrm{n}} \mathrm{mH}_{2} \mathrm{O}$, where $\mathrm{M}^{2+}$ and $\mathrm{M}^{3+}$ are divalent and trivalent metal ions, Ax-n is anion with $\mathrm{n}$ oxidation state or valence, and water of crystallization. The total charge of $\mathrm{LDH}$ is positive due to balancing of negative charge from anion on interlayer space [9].

The LDH has been widely used as adsorbent of various dyes because high surface area properties and also high adsorption capacity. On the other hand, LDH is relative unstable toward reuse material for several times adsorption process, thus modification of $\mathrm{LDH}$ is intriguing topic in order to search stable adsorbent for dyes removal [10]. LDH supported with matrix compounds to form composite is one of the choice to modify LDH. The matrix compounds can be used for composite formation of $\mathrm{LDH}$ is activated carbon [11], graphite [12], and also biochar [13].

Biochar is organic compound, which produced from pyrolysis of renewable feedstock at high temperature such as biomass, agricultural waste, and also rice husk. Biochar as LDH supporting material can be enhanced adsorption capacity, increase the surface area and reduced the agglomeration [14]. Besides, the biochar composites onto LDH can be assumed that produce adequate of hydroxyl on LDH's surface. As confirm as Zhang et al. [15], hydroxyl rich can be affected enhancing adsorption because the generation $\mathrm{H}$-bond between dye molecules and LDH composite biochar. As similarly reported from other researchers, the composite LDH/biochar has been synthesis and applied as adsorbent of dyes. According to Meili et al. [16] Mg-Al LDH/biochar for removal methylene blue. The biochar at that research is produced from bovine bone. The adsorption capacity was $406.47 \mathrm{mg} / \mathrm{g}$. Mg-Al LDH was also used as starting material to functionalize with biochar from date palm. The material was used as adsorbent of methylene blue from aqueous solution with high adsorption capacity until $302.75 \mathrm{mg} / \mathrm{g}$ [17]. Starch-NiFe LDH composite was prepared and used as adsorbent of methyl orange from aqueous solution.<smiles></smiles>

Fig. 1. Methylene blue structure.

The adsorption capacity for this composite reach $387.59 \mathrm{mg} / \mathrm{g}$ [18]. Date palm ash as matrix to form composite with MgAl LDH was studied by [19] to remove methyl orange and eriochrome black- $\mathrm{T}$ from aqueous solution. Based on that information, in this research composite based on $\mathrm{Zn} / \mathrm{Al} \mathrm{LDH}$ and biochar was prepared as adsorbent of methylene blue. The methylene blue is cationic dye as methylthioninium chloride as shown in Fig. 1. Methylene blue is toxic dye and difficult to degrade and can accumulate in aquatic system of environment [20].

Composite of $\mathrm{Zn} / \mathrm{Al}$ LDH-biochar was synthesis by liquid deposition method and characterized by x-ray, FTIR, BET, thermal, and SEM analyses. The adsorption of methylene blue on $\mathrm{Zn} / \mathrm{Al} \mathrm{LDH}$-biochar composite was determined through $\mathrm{pH}$ effect, contact time, initial concentration of methylene blue, and also temperature. The performance of composite on methylene blue adsorption was evaluated by regeneration studied.

\section{Experimental}

\section{Chemicals and Instrumentations}

Chemical reagents in this research was obtained from Merck and Sigma-Aldrich. The chemicals were used after purchased directly such as zinc(II) nitrate, aluminum(III) nitrate, sodium hydroxide, hydrochloric acid, ethanol, acetone, and methylene blue. Water was supplied from Research Center of Inorganic Materials and Complexes FMIPA Universitas Sriwijaya. Water was purified using Purite ${ }^{\circledR}$ ion exchange system for several cycles purification process prior was used. Biochar was obtained local java rice husk and supplied by Bukata Organic. Characterization of material was conducted using x-Ray Rigaku Miniflex-6000 at scan speed 1\%/min. The sample was scanned at diffraction 5-80 . Infra-red spectrum was recorded using FTIR Shimadzu Prestige 21 using $\mathrm{KBr}$ pellet. The sample was mixed with $\mathrm{KBr}$ and vacuum for several minutes. The analysis of infrared was conducted at wavenumber 400-4000 $\mathrm{cm}^{-1}$. The surface area, pore volume, and pore diameter were determined using nitrogen adsorption desorption analysis at $77 \mathrm{~K}$ by ASAP Micrometric apparatus. The sample was vacuumed and degassed several times prior analysis. The thermal analysis was conducted using TG-DTA Shimadzu under nitrogen condition. The morphology of material was analyzed using 
SEM Quanta-650 Oxford Instrument. The analysis of methylene blue from solution was performed using UV-Visible Spectrophotometer Bio-Base BK-UV 1800 PC. The wavelength for methylene blue was $664 \mathrm{~nm}$.

\section{Preparation of $\mathrm{Zn} / \mathrm{Al} \mathrm{LDH}$}

$\mathrm{Zn} / \mathrm{Al} \mathrm{LDH}$ was prepared according to [21] with slight modifications. Solution of zinc(II) nitrate $(100 \mathrm{~mL}, \quad 0.75 \mathrm{M})$ was mixed with solution aluminum(III) nitrate $(100 \mathrm{~mL} 0.25 \mathrm{M})$. The reaction mixture was constantly stirred and solution of sodium hydroxide (2M) was added slowly to achieve $\mathrm{pH} 10$. The $\mathrm{pH} 10$ was adjusted for 4 hours then the reaction mixture was kept at $80^{\circ} \mathrm{C}$ for 5 hours to form white solid material. Solid material was filtered, washed with water several times and dried at $110^{\circ} \mathrm{C}$ for several days.

\section{Preparation of Composite}

Synthesis of ZnAl-biochar composite was conducted by liquid deposition method. Solution of zinc(II) nitrate $(15 \mathrm{~mL}, 0.75 \mathrm{M})$ was mixed with solution of aluminum(III) nitrate $(15 \mathrm{~mL}, 0.25 \mathrm{M})$. The mixture was constantly stirred and $3 \mathrm{~g}$ of biochar was added to these mixtures. The reaction mixture of metal ionbiochar was stirred for several minutes and solution of sodium hydroxide was added slowly until $\mathrm{pH} 10$. The reaction was stirred for 72 hours at $60^{\circ} \mathrm{C}$ to form solid material. Composite was filtered, washed with water several times, and dried at $110^{\circ} \mathrm{C}$ for several days.

\section{Adsorption and Regeneration Process}

Adsorption of methylene blue on composite was studied through $\mathrm{pH}$ effect, effect of contact time, effect of methylene blue concentration, and effect of adsorption temperature. Adsorption was conducted using small batch reactor system equipped with shaker, magnetic bar, and temperature setting. Firstly, effect of $\mathrm{pH}$ medium was studied by adjusted the medium in the range of $\mathrm{pH}$ 2-11. Secondly, effect of adsorption time was studied in the range at 5-200 minutes using $\mathrm{pH}$ optimum at first adsorption process. Thirdly, effect of initial concentration of methylene blue was studied using various concentration of methylene blue at $10,15,20,25,30,35,40$, and $45 \mathrm{mg} / \mathrm{L}$. The concentration was adsorbed at 30, 40, 50, and $60^{\circ} \mathrm{C}$ at optimum $\mathrm{pH}$ and adsorption time from first and second adsorption process. The concentration of methylene from from solution was analyzed using UV-Visible spectrophotometer at $664 \mathrm{~nm}$. Regeneration of adsorbent was performed on used adsorbent. Methylene blue on adsorbent was desorbed with washing acetone following with water several times and dried at $110^{\circ} \mathrm{C}$. Regeneration was conducted at the same procedure as fresh adsorbent. The regeneration was performed until three times cycles of adsorbent.

\section{Results and Discussion}

The analysis results of X-Ray on composite and starting materials was shown in Fig. 2. The diffraction peak of $\mathrm{Zn} / \mathrm{Al} \mathrm{LDH}$ has unique peak at $10.15^{\circ}$ that was identified as well-formed layered structure. That diffraction peak was also having interlayer distance $8.71 \AA$ A. Another diffraction peak was appeared at $60.0^{\circ}$ as anion stage on interlayer distance. Peaks at diffraction in the range $20-35^{\circ}$ are assigned as metal oxide formation on layer structure [22]. The form interlayer of LDH can be calculated by crystallography parameters. According to Sanmunagathan and Elison [23], LDH usually transform as hexagonal shaped which interlayer space is fully of water molecule and anion interlayer. In interlayer, the water molecules was generate the hydrogen-bonded with metal hydroxide layer and anions. Fig. 2b) shows the diffraction of biochar with low crystallinity. The board diffraction peak was found and peak at $22.3^{\circ}$ indicated that organic content on biochar [24]. Composite of ZnAl LDHbiochar has main diffraction peaks at $10,10^{\circ}$, and $21.30^{\circ}$. These diffractions is attributed from diffraction of $\mathrm{LDH}$ and biochar.

The IR spectrum of composite and starting materials are shown in Fig. 3. Zn/Al LDH has vibration at $3446 \mathrm{~cm}^{-1}$ (v O-H stretching), $1620 \mathrm{~cm}^{-1}$ (v O-H bending), $1381 \mathrm{~cm}^{-1}(\mathrm{v} \mathrm{N}-\mathrm{O}$ nitrate) [25]. Biochar is organic compounds thus all vibration was appeared in finger print area at $3446 \mathrm{~cm}^{-1}, 2925 \mathrm{~cm}^{-1}, 28555 \mathrm{~cm}^{-1}$, $1620 \mathrm{~cm}^{-1}, 1435 \mathrm{~cm}^{-1}$, and $1381 \mathrm{~cm}^{-1}$ [24]. Composite has vibration peaks $3446 \mathrm{~cm}^{-1}, 2932 \mathrm{~cm}^{-1}, 2338 \mathrm{~cm}^{-1}$, $1627 \mathrm{~cm}^{-1}$, and $1381 \mathrm{~cm}^{-1}$. The vibration of composite material is combination from vibration of $\mathrm{LDH}$ and biochar. In addition, the composite material was confirmed that the biochar successfully loaded to LDH. As similary reported by Bolbol et al. [26] the presence of two unique vibration of $\mathrm{LDH}$ and biochar can assume that the composite process were successfully

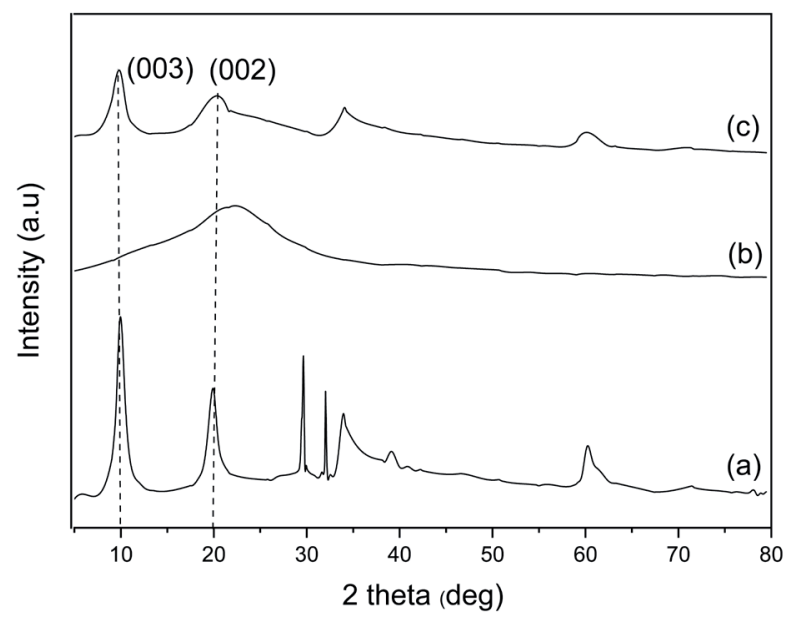

Fig. 2. P-XRD patterns of $\mathrm{Zn} / \mathrm{Al} \mathrm{LDH}$ a), biochar b), and composite c). 


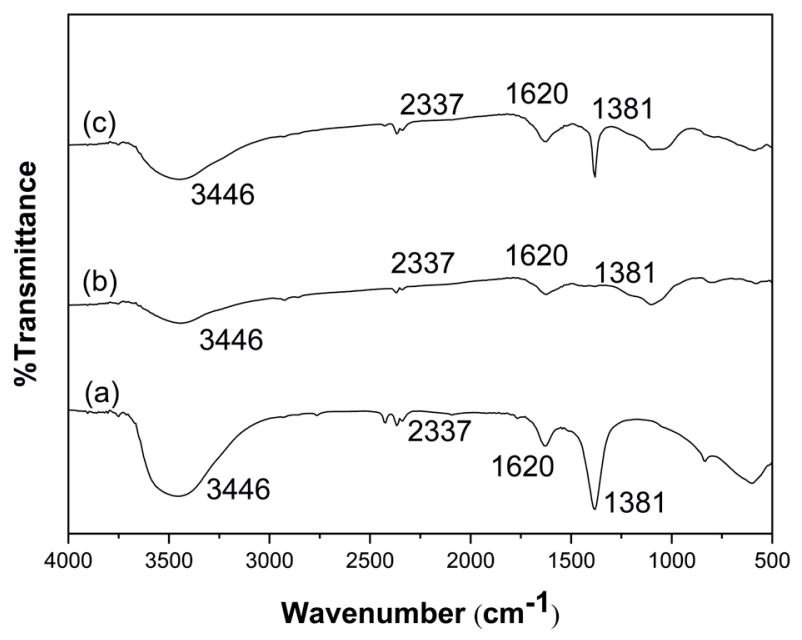

Fig. 3. IR spectrum of $\mathrm{Zn} / \mathrm{Al} \mathrm{LDH}$ a), biochar b), and composite c).

transformed. The nitrogen adsorption desorption isotherm on composite and starting materials was shown in Fig. 4. The adsorption and desorption curves are different on all materials indicated that materials have hysteresis loop. The adsorption desorption curves of materials are classify as type IV adsorption desorption type with macro-porous class [27] and exhibit H4 hysteresis type which can be assumed the hetero-mesoporous. The surface area, pore volume, and pore diameter were obtained from data in Fig. 4 using BET calculation as shown in Table 1.

Composite has slightly larger surface area, pore volume, and pore diameter than starting materials. These phenomena are probably due to formation of macro-porous type composite rather than microporous material. Thus, the increasing the BET properties is not higher than theoretical prediction.

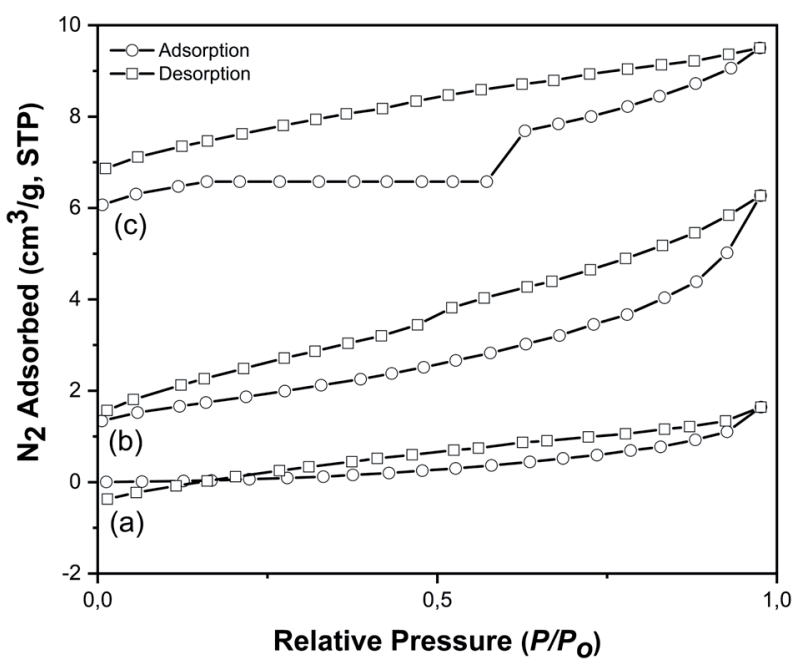

Fig. 4. Nitrogen adsorption desorption of $\mathrm{Zn} / \mathrm{Al} \mathrm{LDH}$ a), biochar b), and composite c).
Table 1. Morphology of materials,

\begin{tabular}{|c|c|c|c|}
\hline Materials & $\begin{array}{c}\text { Surface area } \\
\left(\mathrm{m}^{2 /} \mathrm{g}\right)\end{array}$ & $\begin{array}{c}\text { Pore volume }(\mathrm{BJH}) \\
\left(\mathrm{cm}^{3 /} \mathrm{g}\right)\end{array}$ & $\begin{array}{c}\text { Pore diameter } \\
(\mathrm{BJH})(\mathrm{nm})\end{array}$ \\
\hline Zn-Al LDH & 9.621 & 0.017 & 12.094 \\
\hline Biochar & 50.936 & 0.025 & 12.089 \\
\hline Composite & 58.461 & 0.065 & 12.226 \\
\hline
\end{tabular}

The TG-DTA patterns of composite and starting materials are shown in Fig. 5. Zn/Al LDH has three steps decomposition process. First, the loss of water of crystallization at $110^{\circ} \mathrm{C}$ form endothermic peak. Second, decomposition of nitrate on interlayer $\mathrm{LDH}$ at $230^{\circ} \mathrm{C}$ form endothermic peak, and third, at $610^{\circ} \mathrm{C}$ is decomposition of $\mathrm{LDH}$ form endothermic peak. On the other hand, biochar, which has organic compound has one endothermic peak and one exothermic peak. The endothermic peak at $90^{\circ} \mathrm{C}$ due to loss of water and exothermic peak at $480^{\circ} \mathrm{C}$ due to oxidation of organic compound on biochar. Composite consist of $\mathrm{LDH}$ and biochar thus has two endothermic peaks at $90^{\circ} \mathrm{C}, 210^{\circ} \mathrm{C}$ and one exothermic peak at $500^{\circ} \mathrm{C}$.

Based on BET results before, the composite has not well defined the mesoporous classification material, due to the H4 hysteresis type. Thus, this assumption should be supported by morphology analysis. According to SEM results, the stack layer material of $\mathrm{Zn} / \mathrm{Al} \mathrm{LDH}$ was formed together with small agglomeration species as shown in Fig. 6a). Biochar as shown in Fig. 6b) has irregular pore and shape. On the other hand, composite as shown in Fig. 6c) has layer and block irregular form. That images are appropriate with data of surface area where composite material has relative low surface area due to irregular shape and pore formation.

The adsorption process was first studied through the effect of $\mathrm{pH}$ medium as shown in Fig. 7. The $\mathrm{pH}$ medium was adjusted in the range 2-11 for all adsorbent. Composite has $\mathrm{pH}$ optimum at 5. On the other hand, $\mathrm{ZnAl} \mathrm{LDH}$ and biochar has $\mathrm{pH}$ optimum at 3. The solution of methylene blue has $\mathrm{pH} 3.0-4.3$, thus $\mathrm{pH}$ optimum of medium adsorption in the range of methylene blue adsorption except for composite. These all $\mathrm{pH}$ optimum was used as $\mathrm{pH}$ adsorption.

The effect of methylene blue adsorption time on adsorbents is shown in Fig. 8. The methylene blue adsorption on composite, $\mathrm{ZnAl} \mathrm{LDH}$ and biochar was gradually increased by increasing adsorption time and reach almost 150 minutes to be optimum. The adsorption time of methylene blue was studied by several concentration of methylene blue, where increasing concentration of methylene blue will increase the amount of methylene blue adsorbed. The data in Fig. 8 is used to obtain kinetic adsorption. Kinetic adsorption was calculated using pseudo first-order (PF-O) and pseudo second-order (PS-O) using equation as follows [28]: 

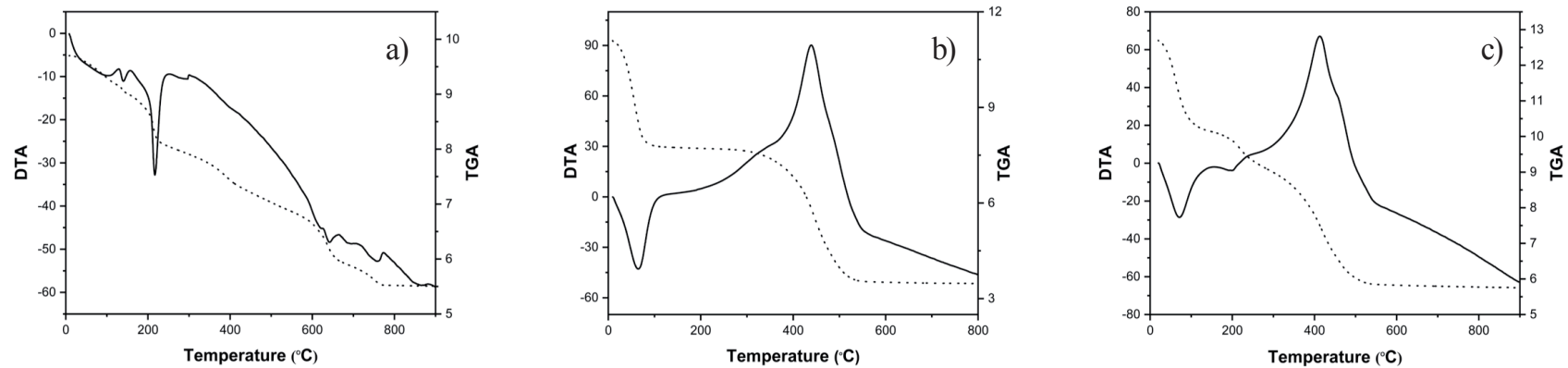

Fig. 5. Thermal profile of materials: $\mathrm{Zn} / \mathrm{Al} \mathrm{LDH}$ a), biochar b), composite c).

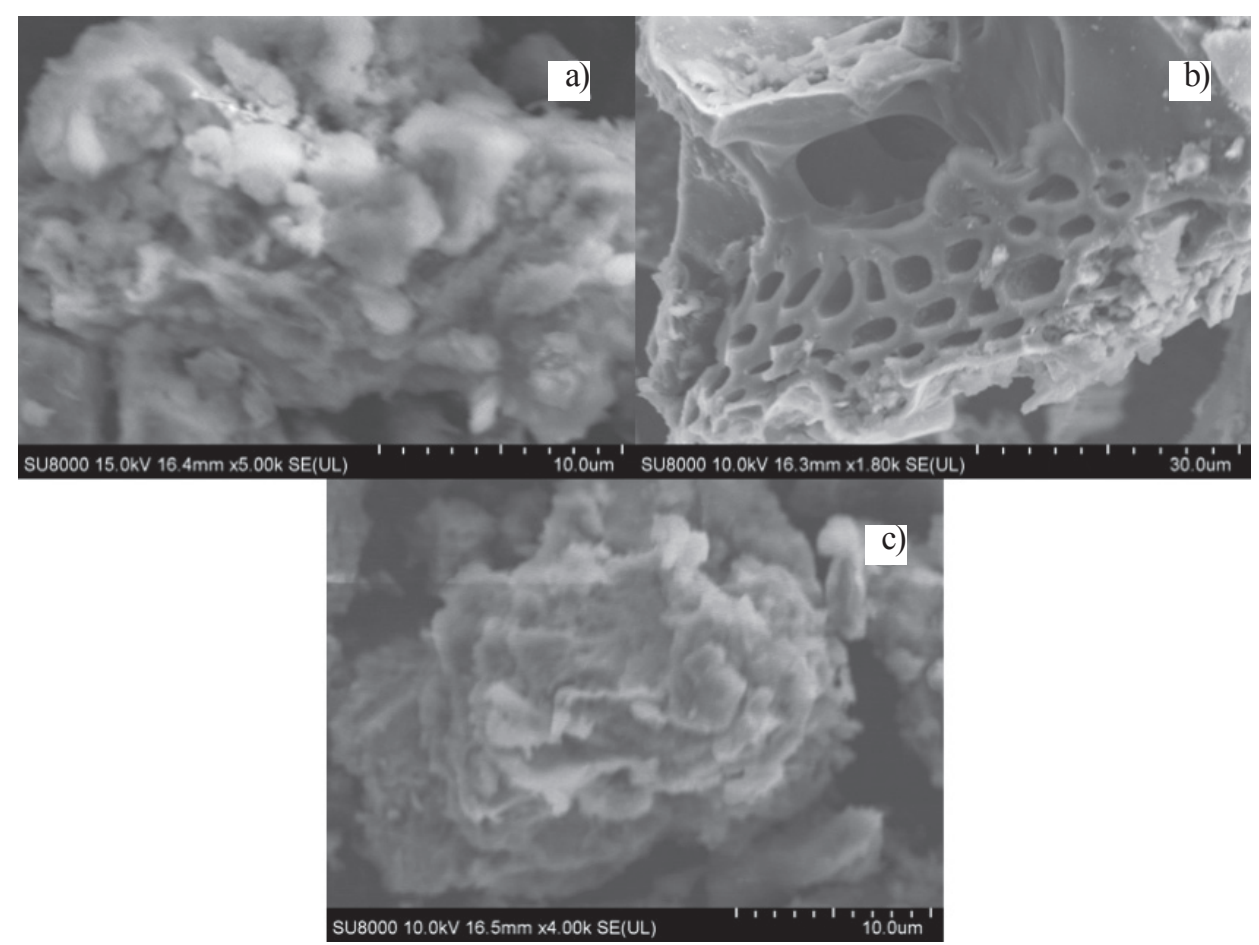

Fig. 6. SEM photos of materials: Zn/Al LDH a), biochar b), composite c).

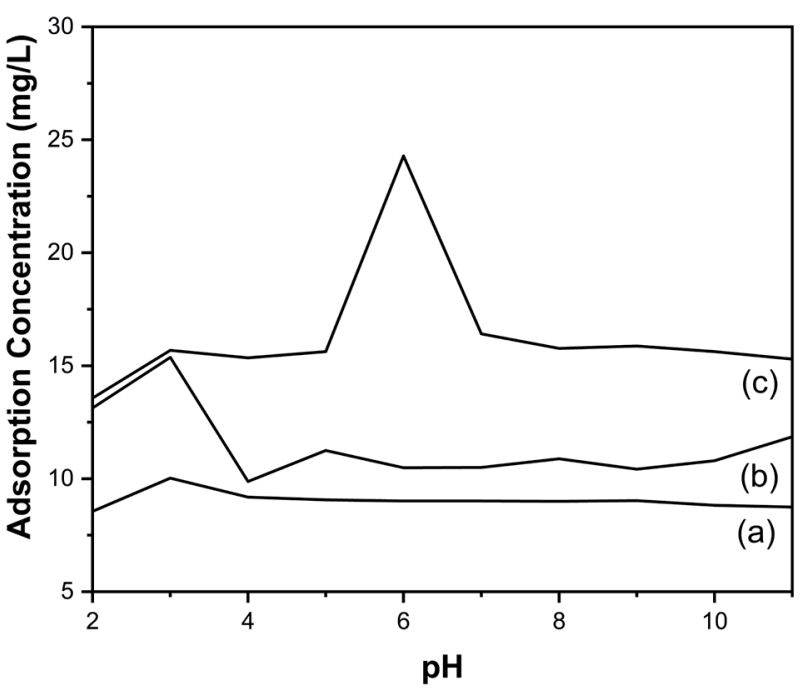

Fig. 7. Effect of $\mathrm{pH}$ adsorption: $\mathrm{Zn} / \mathrm{Al} \mathrm{LDH}$ a), biochar b), composite c).
PF-O model:

$$
\log \left(\mathrm{q}_{\mathrm{e}}-\mathrm{q}_{\mathrm{t}}\right)=\log \mathrm{q}_{\mathrm{e}}-\left(\frac{k_{1}}{2,303}\right) t
$$

...where: $\mathrm{q}_{\mathrm{e}}$ is adsorption capacity at equlibrium $\left(\mathrm{mg} \mathrm{g}^{-1}\right) ; \mathrm{q}_{\mathrm{t}}$ is adsorption capacity at $\mathrm{t}\left(\mathrm{mg} \mathrm{g}^{-1}\right) ; \mathrm{t}$ is adsorption time (minute); and $k_{1}$ is adsorption kinetic rate at pseudo first-order $\left(\right.$ minute $\left.^{-1}\right)$. PS-O model:

$$
\frac{t}{q t}=\frac{1}{k 2 q e^{2}}+\frac{1}{q e} t
$$

...where $\mathrm{q}_{\mathrm{e}}$ is adsorption capacity at equilibrium $\left(\mathrm{mg} \mathrm{g}^{-1}\right) ; \mathrm{q}_{\mathrm{t}}$ is adsorption capacity at $\mathrm{t}\left(\mathrm{mg} \mathrm{g}^{-1}\right)$; $\mathrm{t}$ is adsorption time (minute); and $k_{2}$ is adsorption kinetic rate at pseudo second-order $\left(\mathrm{g} \mathrm{mg}^{-1}\right.$ minute $\left.^{-1}\right)$.

The kinetic model for composite, $\mathrm{ZnAl} \mathrm{LDH}$, and biochar as adsorbents follow PS-O kinetic model due to $\mathrm{R}^{2}$ value. The $\mathrm{R}^{2}$ value is closed to one for PS-O of all adsorbent thus the $k_{2}$ value is the constant rate 
Table 2. Kinetic adsorption of methylene blue on $\mathrm{Zn} / \mathrm{Al} \mathrm{LDH}$, biochar, and composite,

\begin{tabular}{|c|c|c|c|c|c|c|c|c|}
\hline & \multirow{2}{*}{ Adsorbent } & \multirow{2}{*}{$\begin{array}{c}\text { Initial Concentration } \\
(\mathrm{mg} / \mathrm{L})\end{array}$} & \multirow{2}{*}{$\begin{array}{c}\mathrm{Qe}_{\text {experiment }} \\
(\mathrm{mg} / \mathrm{g})\end{array}$} & $\begin{array}{c}\mathrm{Qe}_{\text {Calc }} \\
(\mathrm{mg} / \mathrm{g})\end{array}$ & $\mathrm{R}^{2}$ & $k_{1}$ & \multicolumn{3}{|c|}{$\begin{array}{c}\mathrm{Qe}_{\text {Calc }} \\
(\mathrm{mg} / \mathrm{g})\end{array}$} & $\mathrm{R}^{2}$ & $k_{2}$ \\
\hline $\mathrm{Zn} / \mathrm{Al} \mathrm{LDH}$ & 15 & 1.937 & 3.856 & 0.828 & 0.305 & 2.212 & 0.992 & 0.452 \\
\hline Biochar & 15 & 3.517 & 1.023 & 0.978 & 0.023 & 3.887 & 0.993 & 0.011 \\
\hline Composite & 75 & 15.585 & 13.880 & 0.928 & 0.022 & 17.331 & 0.991 & 0.002 \\
\hline
\end{tabular}
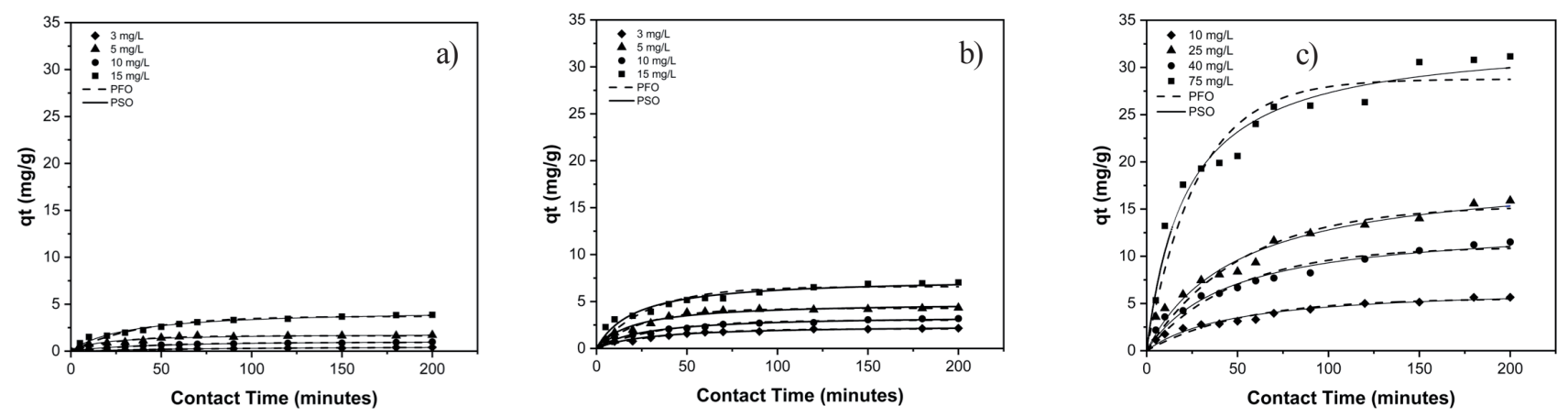

Fig. 8. Effect of adsorption time of methylene blue on $\mathrm{Zn} / \mathrm{Al} \mathrm{LDH}$ a), biochar b), and composite c).
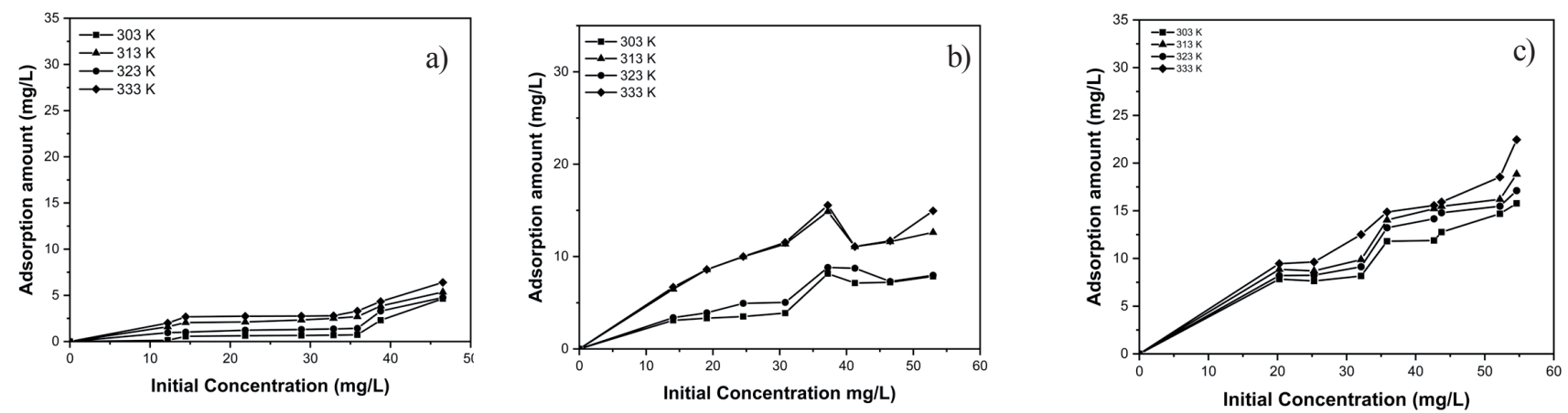

Fig. 9. The effect of initial concentration of methylene blue and temperature adsorption on $\mathrm{Zn} / \mathrm{Al} \mathrm{LDH}$ a), biochar b), and composite c)

Table 3. Thermodynamic parameter of methylene blue adsorption on $\mathrm{Zn} / \mathrm{Al} \mathrm{LDH}$, biochar, and composite,

\begin{tabular}{|c|c|c|c|c|c|}
\hline Adsorbents & $\mathrm{T}(\mathrm{K})$ & $\mathrm{Q}_{\mathrm{e}}(\mathrm{mg} / \mathrm{g})$ & $\Delta \mathrm{H}(\mathrm{kJ} / \mathrm{mol})$ & $\Delta \mathrm{S}(\mathrm{kJ} / \mathrm{mol})$ & $\Delta \mathrm{G}(\mathrm{kJ} / \mathrm{mol})$ \\
\hline & 303 & 15.177 & & & -0.105 \\
\hline Zn/Al LDH & 313 & 19.664 & 21.648 & 0.072 & -0.822 \\
\hline & 323 & 24.698 & & & -1.540 \\
\hline & 333 & 28.761 & & & -2.258 \\
\hline & 303 & 12.630 & & & -7.711 \\
\hline & 313 & 17.845 & 23.697 & & -8.748 \\
\hline & 323 & 23.546 & & & -9.784 \\
\hline & 333 & 25.365 & & & -10.821 \\
\hline Biochar & 303 & 25.002 & & & -0.916 \\
\hline & 313 & 29.065 & 17.309 & & -1.517 \\
\hline
\end{tabular}



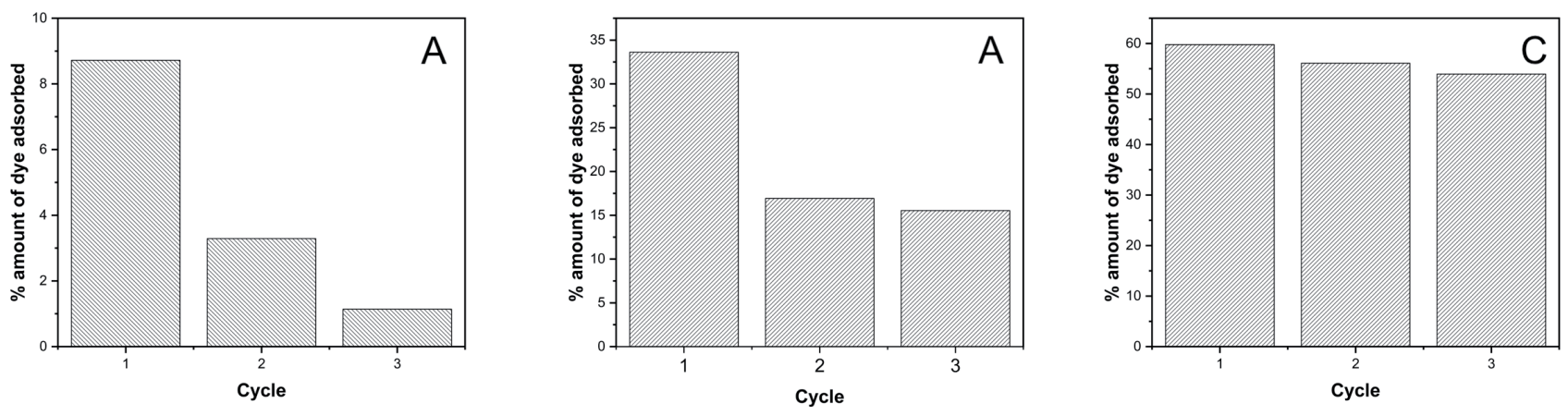

Fig. 10. Cycling process of adsorbent: $\mathrm{Zn} / \mathrm{Al} \mathrm{LDH}$ a), biochar b), composite c)

adsorption in this research. The $k_{2}$ value for adsorbent is in order composite $<$ biochar $<\mathrm{ZnAl} \mathrm{LDH}$. Composite consists of two component i.e LDH and biochar thus reactivity of this adsorbent is low than starting material. $\mathrm{ZnAl} \mathrm{LDH} \mathrm{has} \mathrm{high} \mathrm{reactivity} \mathrm{due} \mathrm{to} \mathrm{inorganic} \mathrm{layer}$ structure assisted the mobility of material-adsorbent to bind each other.

The effect initial concentration of methylene blue adsorption on composite and starting materials at various temperatures is shown in Fig. 9. The adsorption pattern of composite is more quite similar with $\mathrm{Zn} / \mathrm{Al}$ LDH than biochar. There is a flat step adsorption before gradually increased by increasing initial concentration of methylene blue. The pattern also shows two flat curves was formed on composite. These indicated the adsorption was occurred in different active site on composite.

The thermodynamic adsorption data for composite, biochar, and $\mathrm{ZnAl} \mathrm{LDH}$ was obtained from data in Fig. 9. All $\Delta \mathrm{G}$ in Table 3 has negative value means adsorption of methylene blue on composite, biochar, and ZnAl LDH were spontaneously occurred in the small batch reactor system. The $\Delta \mathrm{H}$ for the adsorption in the range of $17.309-23.697 \mathrm{~kJ} / \mathrm{mol}$ and less than $100 \mathrm{~kJ} / \mathrm{mol}$. Thus the adsorption in this research is categorized as physical adsorption [29].

Reuse adsorbent was performed after desorption of methylene blue on adsorbent using acetone, water and dried at $110^{\circ} \mathrm{C}$ overnight. Reuse adsorbent was conducted in three cycles using the same adsorbent for methylene blue adsorption and the results are shown in Fig. 10.

Composite shows the high stability adsorption by reuse adsorbent until three cycles process. On the other hand, $\mathrm{ZnAl} \mathrm{LDH}$ and biochar are unstable adsorbent for reuse process because exfoliated on LDH and organic content stability on biochar. Thus, composite based $\mathrm{ZnAl} \mathrm{LDH} \mathrm{and} \mathrm{biochar} \mathrm{in} \mathrm{this} \mathrm{research} \mathrm{is} \mathrm{potential}$ adsorbent candidate for reusability of methylene blue adsorption.

\section{Conclusions}

Composite based on $\mathrm{Zn} / \mathrm{Al} \mathrm{LDH}-$ biochar has diffraction peaks at $10.10^{\circ}$ and $21.30^{\circ}$ from LDH and biochar. The surface area of composite $\left(58.461 \mathrm{~m}^{2} / \mathrm{g}\right)$ is higher than $\mathrm{Zn} / \mathrm{Al} \mathrm{LDH}\left(9.621 \mathrm{~m}^{2} / \mathrm{g}\right)$ and biochar $\left(50.936 \mathrm{~m}^{2} / \mathrm{g}\right)$. Composite has two endothermic peaks at $90^{\circ} \mathrm{C}$ and $120^{\circ} \mathrm{C}$ due to $\mathrm{LDH}$ and one exothermic peak at $500^{\circ} \mathrm{C}$ due to biochar. Composite and starting materials follow pseudo second-order kinetic model and adsorption was spontaneous occurred and categorized as physical adsorption. Composite has high adsorbent reusability properties and can be used as potential adsorbent candidate for removal methylene blue from aqueous solution.

\section{Acknowledgements}

Authors thank Universitas Sriwijaya through Hibah Profesi 2020 for support of this research also to Research Center of Inorganic Materials and Complexes FMIPA Universitas Sriwijaya for instrumental analysis.

\section{Conflict of Interest}

The authors declare no conflict of interest

\section{References}

1. MitTAL A., MitTAL J., MALVIYA A., GUPTA V.K. Journal of Colloid and Interface Science Adsorptive removal of hazardous anionic dye "Congo red" from wastewater using waste materials and recovery by desorption, J. Colloid Interface Sci., 340 (1), 166, 2009.

2. FAN S., WANG Y., WANG Z., TANG J., TANG J., LI $X$. Removal of methylene blue from aqueous solution by sewage sludge-derived biochar: Adsorption kinetics, equilibrium, thermodynamics and mechanism, J. Environ. Chem. Eng., 5 (1), 601, 2017.

3. LEÓN O. et al., Removal of anionic and cationic dyes with bioadsorbent oxidized chitosans, Carbohydr. Polym., 194, 375, 2018.

4. XU Y., LI Z., SU K., FAN T., CAO L. Mussel-inspired modification of PPS membrane to separate and remove the dyes from the wastewater, Chem. Eng. J., 341 371, 2018.

5. KUSHWAHA A.K., GUPTA N., CHATTOPADHYAYA M.C. Removal of cationic methylene blue and malachite 
green dyes from aqueous solution by waste materials of Daucus carota, J. Saudi Chem. Soc., 18 (3), 200, 2014.

6. ABIDI N. et al., Removal of anionic dye from textile industries' effluents by using Tunisian clays as adsorbents. Zeta potential and streaming-induced potential measurements, Comptes Rendus Chim., 22 (2-3), 113, 2019.

7. ZUBIETA C., SIERRA M.B., MORINI M.A., SCHULZ P.C., ALBERTENGO L., RODŔGUEZ M.S. The adsorption of dyes used in the textile industry on mesoporous materials, Colloid Polym. Sci., 286 (4), 377, 2008.

8. RAMADHAN J., PALAPA N.R., TAHER T., MOHADI R., LESBANI A. Intercalation $\mathrm{Zn} / \mathrm{Cr}$ Layered Double Hydroxides with $\mathrm{K} 3 \quad[\alpha-\mathrm{PW} 12 \mathrm{O} 40] \mathrm{nH}_{2} \mathrm{O}$ and $\mathrm{K} 4$ $[\alpha-\mathrm{SiW} 12 \mathrm{O} 40] \mathrm{nH}_{2} \mathrm{O}$ as Adsorbent of Rhodamine-B, Sci. Technol. Indones., 4 (4), 109, 2020.

9. ZHENG Y., CHENG B., YOU W., YU J., HO W. 3D hierarchical graphene oxide-NiFe LDH composite with enhanced adsorption affinity to Congo red, methyl orange and $\mathrm{Cr}(\mathrm{VI})$ ions, J. Hazard. Mater., 369 (September 2018), 214, 2019.

10. OKTRIYANTI M., PALAPA N.R., LESBANI A. Effective Removal of Iron (II) from Aqueous Solution by Adsorption using $\mathrm{Zn} / \mathrm{Cr}$ Layered Double Hydroxides Intercalated with Keggin Ion, J. Ecol. Eng., 21 (5), 63, 2020.

11. TUZEN M., SARI A., SALEH T.A. Response surface optimization, kinetic and thermodynamic studies for effective removal of rhodamine $\mathrm{B}$ by magnetic $\mathrm{AC} / \mathrm{CeO}_{2}$ nanocomposite, J. Environ. Manage., 206, 170, 2018.

12. LINGHU W., YANG H., SUN Y., SHENG G., HUANG Y. One-pot synthesis of $\mathrm{LDH} / \mathrm{GO}$ composites as high effective adsorbent for the decontamination of $\mathrm{U}$ (VI) One-pot synthesis of $\mathrm{LDH} / \mathrm{GO}$ composites as high effective adsorbent for the decontamination of U (VI), VI, 2017.

13. TAN Y., YIN X., WANG C., SUN H., MA A., ZHANG G., WANG N. Sorption of cadmium onto $\mathrm{Mg}-\mathrm{Fe}$ Layered Double Hydroxide (LDH)-Kiwi branch biochar. Environmental Pollutants and Bioavailability 31 (1), 189, 2019.

14. PALAPA N.R., TAHER T., RAHAYU B.R., MOHADI R., RACHMAT A., LESBANI A. CuAl LDH/Rice Husk Biochar Composite for Enhanced Adsorptive Removal of Cationic Dye from Aqueous Solution, Bull. Chem. React. Eng. Catal., 15 (2), 525, 2020.

15. ZHANG J., XU D., QIAN W., ZHU J., YAN F. Host-guest inclusion complexes derived heteroatom-doped porous carbon materials, Carbon N. Y., 105, 183, 2016.

16. MEILI L., LINS P.V., ZANTA C.L.P.S., SOLETTI J.I., RIBEIRO L.M.O., DORNELAS C.B., VIEIRA M.G.A. MgAl-LDH/Biochar composites for methylene blue removal by adsorption. Applied Clay Science, 168, 11, 2019.

17. ZUBAIR M., SAOOD M., DALHAT N., ANIL I. Applied Clay Science Functionalized MgAl-layered hydroxide intercalated date-palm biochar for Enhanced Uptake of Cationic dye: Kinetics, isotherm and thermodynamic studies, Appl. Clay Sci., 190 (March), 105587, 2020.
18. ZUBAIR M., JARRAH N., KHALID A., SAOOD M. Starch-NiFe-layered double hydroxide composites: Efficient removal of methyl orange from aqueous phase, J. Mol. Liq., 249, 254, 2018.

19. BLAISI N.I., ZUBAIR M., ALI S., KAZEEM T.S. Date palm ash-MgAl-layered double hydroxide composite: sustainable adsorbent for effective removal of methyl orange and eriochrome black-T from aqueous phase, 2018.

20. SEFTEL E.M., POPOVICI E., BEYERS E., MERTENS M., ZHU H.Y., VANSANT E.F., COOL P. New $\mathrm{TiO}_{2} / \mathrm{MgAl}-\mathrm{LDH}$ nanocomposites for the photocatalytic degradation of dyes. Journal of nanoscience and nanotechnology, 10 (12), 8227, 2010.

21. CHILUKOTI S., THANGAVEL T. Enhanced adsorption of Congo red on microwave synthesized layered $\mathrm{Zn}-\mathrm{Al}$ double hydroxides and its adsorption behaviour using mixture of dyes from aqueous solution, Inorg. Chem. Commun., 100 (December 2018) 107, 2019.

22. ZHANG Q., JIAO Q., LEROUX F., TANG P., LI D., FENG Y. Antioxidant intercalated hydrocalumite as multifunction nanofiller for Poly(propylene): Synthesis, thermal stability, light stability, and anti-migration property, Polym. Degrad. Stab., 140, 9, 2017.

23. SHANMUGANATHAN K., ELLISON C.J. Layered Double Hydroxides: An Emerging Class of Flame Retardants. Elsevier B.V., 2014.

24. XU X., CAO X., ZHAO L. Comparison of rice huskand dairy manure-derived biochars for simultaneously removing heavy metals from aqueous solutions: Role of mineral components in biochars, Chemosphere, 92 (8), 955, 2013.

25. GEORGE G., SARAVANAKUMAR M.P. Facile synthesis of carbon-coated layered double hydroxide and its comparative characterisation with $\mathrm{Zn}-\mathrm{Al} \mathrm{LDH}$ : application on crystal violet and malachite green dye adsorptionisotherm, kinetics and Box-Behnken design, Environ. Sci. Pollut. Res. Int., 25 (30), 30236, 2018.

26. BOLBOL H., FEKRI M., HEJAZI-MEHRIZI M. Layered double hydroxide-loaded biochar as a sorbent for the removal of aquatic phosphorus: behavior and mechanism insights, Arab. J. Geosci., 12 (16), 2019.

27. MOHAMED F., ABUKHADRA M.R., SHABAN M. Removal of safranin dye from water using polypyrrole nanofiber/Zn-Fe layered double hydroxide nanocomposite (Ppy NF/Zn-Fe LDH) of enhanced adsorption and photocatalytic properties, Sci. Total Environ., 640-641, 352, 2018

28. DOS SANTOS R.M.M., GONÇALVES R.G.L., CONSTANTINO V.R.L., SANTILLI C.V., BORGES P.D., TRONTO J., PINTO F.G. Adsorption of Acid Yellow 42 dye on calcined layered double hydroxide: Effect of time, concentration, $\mathrm{pH}$ and temperature. Applied Clay Science, 140, 132, 2017.

29. LESBANI A., TAHER T., PALAPA N.R., MOHADI R., RACHMAT A. Preparation and utilization of Keggintype polyoxometalate intercalated $\mathrm{Ni}-\mathrm{Fe}$ layered double hydroxides for enhanced adsorptive removal of cationic dye. SN Applied Sciences, 2 (3), 1, 2020. 